\title{
Anastrozole Reduce Cell Proliferation and Induce Apoptosis in Glioblastoma Multiforme Xenograft Mouse Model
}

Irene G Aguilar-García', María de la Galván-Ramírez', Sergio H Dueñas-Jiménez², Rolando Castañeda-Arellano³, Jorge D. Rivas-Carrillo', Erika P. Domínguez-Rangel ${ }^{1}$, and Judith M Dueñas-Jiménez ${ }^{1 *}$

${ }^{1}$ Department of Physiology, University Center of Health Sciences, University of Guadalajara, Jalisco, Mexico cinvestav, IPN, Mexico City, Mexico ${ }^{2}$ Department of Neurosciences, University Center of Health Sciences, University of Guadalajara, Jalisco, Mexico cinvestav, IPN, Mexico City, Mexico ${ }^{3}$ Department of Physiology, Biophysics and Neurosciences, University of Guadalajara, Jalisco, Mexico cinvestav, IPN, Mexico City, Mexico

\begin{abstract}
Objective: Glioblastoma multiforme is the most aggressive form of primary brain tumors, characterized by a high molecular heterogeneity hinder its treatment. Glioblastoma multiforme cells synthesize steroids through the enzyme aromatase and express estrogen receptors. Anastrozole, a specific aromatase inhibitor, plays an important role in endocrine therapy for breast cancer treatment. However, it is unknown whether this inhibitor is useful for treating glioblastoma multiforme. The aim of this work was evaluated the anastrozole effects in the viability and proliferation of malignant cells $\mathrm{C} 6$ in vitro as well as apoptosis, cell division, aromatase and estrogen receptor alpha expression in a GBM model in vivo.
\end{abstract}

Methods: C6 cells viability under anastrozole treatment $(25,50,75 \mu \mathrm{g} / \mathrm{ml})$ was measured by MTT method and their proliferation was determinate by immunohitofluorescence. In the tumor tissue, the proliferation was evaluated using ki-67 antibody by immunohistofluorescence. ER alpha, aromatase, caspase 8 and 9 protein expression was analyzed using western-blotting. Furthermore, GPR-30, SOX2, CD133 and GFAP were evaluated by immunohistofluorescence.

Results: Anastrozole produced a reduction in the viability and proliferation of the C6 cells in culture when was used at $50 \mu \mathrm{g} / \mathrm{ml}$. It reduces the number of Ki67 immunofluorescent cells in approximately $50 \%$. The aromatase expression decreased in $95 \%$. The estrogen receptor alpha expression increased by a $20 \%$ approximately. Caspase 8 expression increased in the treated tumor tissue, although it was undetectable in the not treated group. Caspase 9 increased in approximately $95 \%$ in the treated group. All data expressed in these experimental quantifications have a statistically significant difference $(p<0.05)$. $G$ protein coupled receptor-30 was observed in the tumor specimens exhibiting an expression reduction in the anastrozole treated group.

Conclusion: The present study demonstrates that anastrozole reduces viability and proliferation in vitro, induces apoptosis and reduces proliferation and aromatase expression in the glioblastoma Xenograft mouse model.

Keywords: Anastrozole; Glioblastoma multiforme; Xenograft; Proliferation; Apoptosis; Estrogen receptor; Aromatase

\section{Introduction}

Glioblastoma multiforme primary is the most malignant form of astrocytomas, with a high capacity of cell proliferation and tumor invasion. Extensive work in glioblastoma gene expression profile has been done in recent years (Cancer Genome Atlas Research Network) [1]. Glioblastoma is a heterogeneous tumor with multiple redundant intracellular pathways, generating several subtypes [2]

GBM patient survival is approximately 24 months after diagnostic. The world incidence is about 5.5/100,000 of human beings. The treatment includes surgical tumor resection, chemotherapy and radiotherapy. Temozolamide is the most used medication for GBM treatment. However, it has important side effects, such as myelosuppression and low apoptotic activity in malignant cells; many patients developed resistance to this drug.

Estrogens promote the cancer growth in breast, lung, prostate and endometrium [3-5]. Aromatase is an enzyme that converts androgens in estrogens. Therefore, an alternative or additional treatment could include inhibitors of aromatase. Human astrocytomas express aromatase mRNA and the highest expression is in GBM and is associated to the worst patient survival outcome. Estrogen receptor alpha (ER $\alpha)$ expression decreases in high degree astrocytomas [6]. It is important to mention that its expression also has been described in rat and human glioblastoma cell lines [7]. ER $\alpha$ expression varies in diverse tumors types including endometrial, lung and breast cancer. Its decrease in expression is caused by ESR1 gene promotor hypermethylation [8]. In addition to ERa, there are other types of estrogen receptors, such as ER $\beta$ which expression also varied, depending on the astrocytoma degree of malignancy. Furthermore, there is a $G$ protein-coupled receptor 30 in cell membrane (GPR30). The function of this receptor has not been analyzed in GBM cells. GPR30 activates rapid membrane cellular pathways including mitogen-activated protein kinase (MAPK) and kinase protein inositol 3 phosphates (IP3K) implied in promoting cell proliferation. However, its function deserves further analysis, given that it has not been studied extensively in the brain [9].

*Corresponding author: Judith Marcela Dueñas Jimenez, Department of Physiology, University Center of Health Sciences, University of Guadalajara, Jalisco, Mexico cinvestav, IPN, Mexico City, Mexico, Tel: 52133 10585313; E-mail: judithmarceladuenas@gmail.com

Received August 16, 2017; Accepted September 18, 2017; Published September 20, 2017

Citation: Aguilar-García IG, Galván-Ramírez MD, Dueñas-Jiménez SH Castañeda-Arellano R, Rivas-Carrillo JD, et al. (2017) Anastrozole Reduce Cell Proliferation and Induce Apoptosis in Glioblastoma Multiforme Xenograft Mouse Model. J Cancer Sci Ther 9: 655-660. doi:10.4172/1948-5956.1000488

Copyright: () 2017 Aguilar-García IG, et al. This is an open-access article distributed under the terms of the Creative Commons Attribution License, which permits unrestricted use, distribution, and reproduction in any medium, provided the original author and source are credited. 
Citation: Aguilar-García IG, Galván-Ramírez MD, Dueñas-Jiménez SH, Castañeda-Arellano R, Rivas-Carrillo JD, et al. (2017) Anastrozole Reduce Cell Proliferation and Induce Apoptosis in Glioblastoma Multiforme Xenograft Mouse Model. J Cancer Sci Ther 9: 655-660. doi:10.4172/19485956.1000488

GPR30 has been mainly studied in endometrial carcinoma, with a high expression in relation to non-tumor tissues, suggesting that this receptor plays a key role in tumor growth [10]. The expression of this receptor has not been studied in GBM. Therefore, GPR30 was assessed in this study.

At present time, is unknown whether $17 ß$-estradiol promotes GBM cell proliferation and tumor progression. New alternatives, such as the use of aromatase inhibitors (AIs) could be a good medication with minimum patient side effects. Anastrozole (AI) is highly efficient in breast cancer treatment, particularly in post-menopause women. [11]. In addition, studies of pharmacodynamic and collateral effects indicate that this drug could be suitable for GBM treatment. In this study, anastrozole effects on viability, proliferation, estrogen receptor expression (ERaand GPR30) and apoptosis was evaluated in a GBM in model in vivo and tumor $\mathrm{C} 6$ cells in vitro.

\section{Materials and Methods}

\section{Ethical considerations}

All procedures were performed according to the ethical guidelines of Mexican Official Norm (NOM-062-ZOO-1999), the National Institute of Health, NIH publication No. 8023 (1996), and the Guidelines for the Care and Use of Laboratory Animals Board, CUCS, U. de G., (IACUC).

\section{Cell culture}

C6 cells were cultured in DMEM-F12 medium high in glucose (Caisson DFL-14), supplemented with $10 \%$ fetal bovine serum, penicillin $(50 \mathrm{U} / \mathrm{ml})$ and streptomycin $(50 \mathrm{U} / \mathrm{ml}$ ) (Corning 30-002$\mathrm{CL}$ ). The cells were incubated at $37^{\circ} \mathrm{C}$, in an atmosphere containing 95\% air and $5 \% \mathrm{CO}_{2}$. The cells were then separated from the plate for use in the in vitro experiments or further striatum Xenograft in Balb C/ nude mice.

\section{MTT assay}

C6 Cells were seeded in 96 well plates (50,000 cells per well) and treated with 25,50 and $75 \mu \mathrm{g} / \mathrm{ml}$ anastrozole. They were then incubated for $48 \mathrm{~h}$, each dose in five different wells using five different plates. Each well was supplied with $10 \mu \mathrm{l}$ of tetrazolium salt and $100 \mu \mathrm{l}$ of $\mathrm{N}$ 'N- dimethylformamide (Bio Basic Inc). The untreated cells were considered as control. Then, the plates were incubated again for 24 hours, at $37^{\circ} \mathrm{C}$. Finally, reading in the Dynex MRX USA microplate reader was at $450 \mathrm{~nm}$.

\section{Immunocytofluoresence}

The cells were fixed during 15 minutes at room temperature in a $4 \%$ paraformaldehyde in PBS (pH7.4) solution. Then cells were washed with $0.01 \mathrm{M}$ PBS and incubated for $1 \mathrm{~h}$ in a solution containing $10 \%$ normal goat serum, $0.25 \%$ triton X-100, $1 \%$ BSA. Incubation was performed at room temperature. Subsequently, the cells were incubated with the mouse monoclonal antibody anti-ki67 (ab16667 this for $24 \mathrm{~h}$ at $4^{\circ} \mathrm{C}$ ) diluted at $1: 250$. Then, the plate was incubated with an antibody alexa fluor 488 rabbit polyclonal (1:1000, abcam ab 159977) for $2 \mathrm{~h}$ at room temperature. Afterwards, the cells were stained with DAPI $(20 \mu \mathrm{l})$ for 5 minutes. Then a mounting medium was used to seal the coverslips. For observing the slides, we used a laser confocal scanning microscope (Leica TCS-SPE) equipped with a 40 oil-immersion objective and Leica LAS AF lite software (Leica Microsystems, Wetzlar, Germany). Ki67 immunofluorescent cells were counted in 15 fields of $50 \mu \mathrm{m}^{2}$.

\section{Glioblastoma xenograft mouse model}

Forty-six to 8-week-old male Balb-C/nude mice were used. The mice were divided into a control group (animal with C6 implanted cells but anastrozole) and one experimental group of four animals treated with anastrazole $(0.1 \mathrm{mg} / \mathrm{Kg})$. To make the C6 cells xenograft, the mice were anesthetized using 3\% sevofluorane for inducing anesthesia. An incision in the brain medium line was made and a small hole in the skull was made. A total of 1 X106 C6 cells diluted in $2 \mu \mathrm{L}$ DMEM-F12 medium were injected in the left striatum following the stereotaxic coordinates $(\mathrm{X}=1.34 \mathrm{~mm}, \mathrm{Y}=1.5 \mathrm{~mm}$ and $\mathrm{Z}=3.5 \mathrm{~mm})$.

\section{Drug preparation and administration}

Anastrozole (Sigma Aldrich A2736) was dissolved in a solution of $0.1 \mathrm{mM}$ DMSO in order to obtain a final concentration of $500 \mu \mathrm{g} / \mathrm{ml}$ (stock solution), which was stored at $-20^{\circ} \mathrm{C}$. The drug was administered at $0.1 \mathrm{mg} / \mathrm{kg}$ for seven days post-xenograft, in a tail vein.

\section{Immunohistofluorescence}

Five to ten coronal brain sections $(30 \mu \mathrm{m})$ were placed in a $0.2 \%$ X-100 triton solution for one hour. Then a $10 \%$ goat serum solution was added for two hours. Subsequently, a specific immunostaining was performed with different antibodies. The antibodies individually used were, anti-ki67 mouse monoclonal (1:250, abcam ab16667); antiaromatase mouse monoclonal (1:250, abcam ab139492); anti- caspase 9 polyclonal rabbit (1:300, Santa Cruz Technology sc-8355), anti-caspase 8 polyclonal goat (1:250, Santa Cruz Technology sc-6134); anti-GFAP monoclonal cow (1:750, DAKO, Z0334, RRID: AB_100103382), antiCD133 rabbit polyclonal (1:300, Santa Cruz Technology sc -30219), anti-SOX2 polyclonal goat (1:300, Santa Cruz Technology sc-17320), anti ERa mouse monoclonal (1:500, abcam ab 66102) and antiGPR30 rabbit polyclonal (1:300, abcam ab 39742). All the incubations for the previously mentioned antibodies were made at $4^{\circ} \mathrm{C}$ for 24 h. Then, secondary antibodies were used according the respective primary antibody. The secondary antibodies used were alexa fluor 488 polyclonal rabbit (1:1000, abcam ab 159977); alexa fluor 594 polyclonal rabbit (1:1000, abcam ab150080); then were added to tissue sections and incubated for two hours at room temperature. The cellular nucleus was stained using $20 \mu \mathrm{L}$ DAPI solution. For observing and analyzing the sections, we use a laser confocal scanning microscope (Leica TCS-SPE), equipped with a 40 oil-immersion objective and a Leica LAS AF lite software (Leica Microsystems, Wetzlar, Germany). ImageJ Program was employed for analyzing the image.

\section{Western blot}

The proteins were obtained using a lysis buffer containing a COMPLETE protease inhibitor cocktail. Protein quantification was performed using the Bradford method. Aliquots containing $50 \mu \mathrm{g}$ of protein were separated on $10 \%$ SDS-PAGE gels and transferred to polyvinyl denedifluoride (PVDF) membranes (BioRad, Hercules, CA). Then, the membranes were blocked by $5 \%$ nonfat milk with TBST ( $0.05 \%$ Tween-20, Triton buffer solution) for one hour at room temperature. The membranes with the specific primary antibodies were incubated: anti-aromatase mouse monoclonal (1:250, abcam ab139492); anti- caspase 9 polyclonal rabbit (1: 300, Santa Cruz Technology sc-8355), anti-caspase 8 polyclonal goat (1:250, Santa Cruz Technology sc-6134); and anti- $\beta$ actin rabbit polyclonal 1:300, abcam ab 8227 ) at $4^{\circ} \mathrm{C}$ for 24 hours. The membranes were then incubated for 2 hours at room temperature with secondary antibodies; antimouse IgG HRP conjugated (1:2000); anti rabbit HRP conjugated (1:4000); anti-goat IgG (1:5000). A new incubation was made in an avidin-biotin solution (ABC standard kit, VECTOR) for 45 minutes at room temperature. The membranes were washed five times with Tris- $\mathrm{NaCl}$ and Tween 20 buffer (TBST), and were revealed using 3-3' 
Citation: Aguilar-García IG, Galván-Ramírez MD, Dueñas-Jiménez SH, Castañeda-Arellano R, Rivas-Carrillo JD, et al. (2017) Anastrozole Reduce Cell Proliferation and Induce Apoptosis in Glioblastoma Multiforme Xenograft Mouse Model. J Cancer Sci Ther 9: 655-660. doi:10.4172/19485956.1000488

diaminobenzidine (D-5905, Sigma) according to the manufacturer's instructions. Images were digitally acquired by a BioDoc-It Imaging System (UVP), and then, the optic integrated density was measured with an ImageJ gel analyze program.

\section{Statistics}

Data obtained in vivo and in vitro experiments were expressed as media \pm standard error or standard deviation. A student $t$ test was applied for determining the difference between groups. A MannWhitney $U$ was used to analyze the data of the apoptosis experiments, $\mathrm{ER} \alpha$ and aromatase expression. Data of proliferation and viability experiments analysis was performed by ANOVA test. The significant difference was considered as $\mathrm{p}<0.05$.

\section{Results}

\section{Cell viability}

C6 cell viability decreased $40 \%$ by Anastrozole $(25 \mu \mathrm{g} / \mathrm{ml})$ when was compared to the control, with a significant difference of $\mathrm{p}(<0.05)$. In the cultures treated with 50 and $75 \mu \mathrm{g} / \mathrm{ml}$ anastrozole, reduced $95 \%$ cell viability compared to control group, with a significant difference of $\mathrm{p}<0.001$ (Figure 1).

\section{Cell proliferation}

Anastrozole used in all doses considerably reduced the C6 cells proliferation in culture. The $50 \mu \mathrm{g} / \mathrm{ml}$ dose had the maximally effect in reducing cell proliferation. The Ki67 immunopositive cells decreased approximately $50 \%$, with a significant difference $\mathrm{p}<0.001$ (Figure 2 ).

In the Xenograft GBM model mice, the tumor grew, infiltrating and surrounding brain tissue and exhibiting a high vascularization pattern (Figure 3). Tumor tissue analysis by antibody anti-GFAP recognizing astrocytes clearly showed morphological changes. In Figure $4 \mathrm{~A}$, the presence of reactive gliosis with a marked number of GFAP immunopositive astrocytes configured in a palisade arrangement was observed around the lesion. Furthermore, the astrocyte dendrites were longer and thinner that in normal astrocytes. The contralateral hemisphere exhibited a low number of GFAP immunoreactive cells with a classical stellate morphology (Figure 4B). The tumor tissue also exhibited immunoreactivity to CD133 (Figures 4C-4E) and SOX2 (Figures $4 \mathrm{~F}-4 \mathrm{H}$ ), confirming the malignity of these cells.

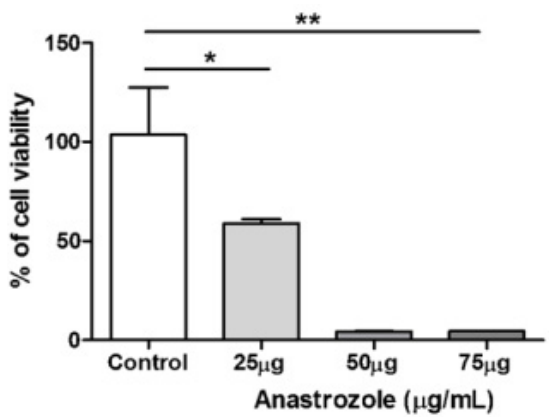

Figure 1: Effect of anastrozole on glioblastoma cell viability. C6 cell viability was assessed by a MTT assay 48 hours after the treatment with anastrozole at different doses: 25,50 and $75 \mu \mathrm{g} / \mathrm{ml}$. When cells were treated with $25 \mu \mathrm{g} /$ $\mathrm{ml}$, they decreased approximately $40 \%$, as compared to control $\left({ }^{*} p<0.05\right)$ The decrease was greater with doses of $50,75 \mu \mathrm{g} / \mathrm{ml}$ as illustrated in the graph $\left({ }^{*} p<0.001\right)$. Each column represents the mean $\pm S D$, data were analyzed using two-way ANOVA, followed by a Dunnet post-hoc test; $n=5$ experiments for each dose.

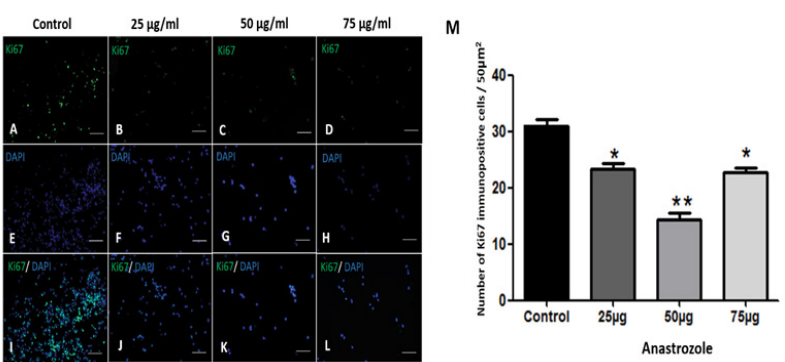

Figure 2: Effect of anastrozole on glioblastoma cell proliferation. A-D, C6 cells images stained with anti-Ki67. The dose of anastrozole is indicated on each bar at the top of the figure. E-H, the nucleus was stained with DAPI. I-L show the ki67 and DAPI merge. M, graph shows the immunopositive cells to Ki67 in a 50 $\mu \mathrm{m}^{2}$ area, in regard to anastrozole doses. Notice the anastrozole reduced the number of Ki67 immunopositive cells, at all doses used. The larger anastrozole effect was produced at $50 \mu \mathrm{g} / \mathrm{ml}$ with a significant difference with respect to the control $p<0.001\left(^{* *}\right)$. The cell proliferation reduction was also statistical significant for doses of 25 and $\left.75 \mu \mathrm{g} / \mathrm{ml} \mathrm{p}<0.05{ }^{*}\right)$. Each column represents the mean \pm $\mathrm{SD}$, data were analyzed using two-way ANOVA. Scale bar=50 $\mu \mathrm{m}$.

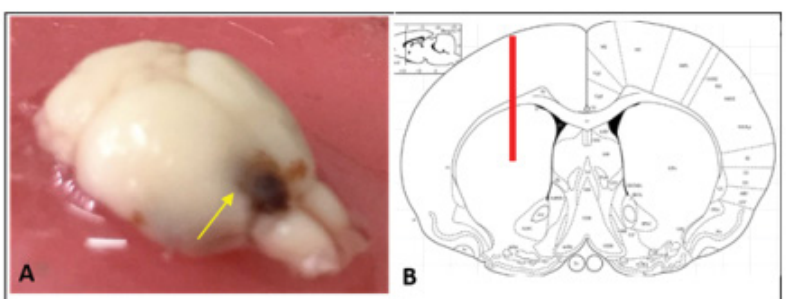

Figure 3: Orthotopic xenograft tumor in brain. Panel A, exhibits the brain after being perfused with paraformaldehyde. The tumor is invading neighboring areas including those in the contralateral side, as seen visually. Panel $B$, shows the stereotaxic coordinates $(X=1.34 \mathrm{~mm}, Y=1.5 \mathrm{~mm}$ and $Z=3.5 \mathrm{~mm})$ for the situ where $\mathrm{C} 6$ cells were injected. It corresponds to the striatum.

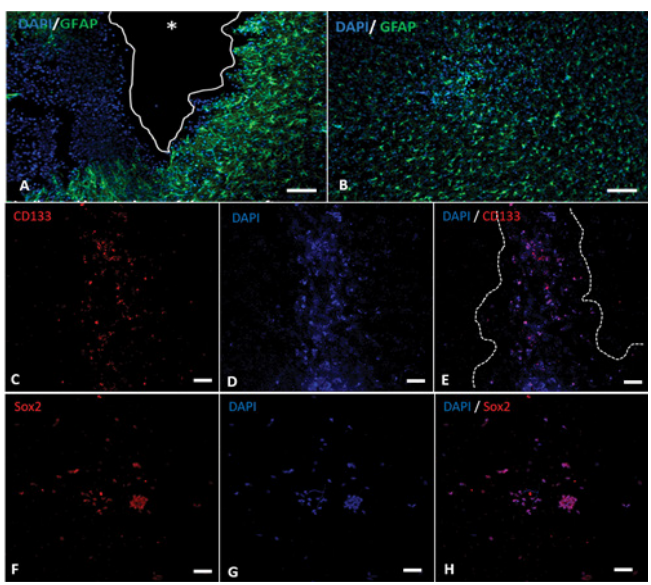

Figure 4: Specific tumor markers in glioblastoma. Sections tumor tissue in panel A show cells marked with anti-GFAP and the presence of reactive gliosis near to the penetrating lesson (drawn by hand). Notice, a big number of immunopositive GFAP cells (green marked cells). These glial cells exhibit a palisade-like arrangement in their cell process, irradiating out from the border of the tumor mass. $B$, the image shows the contralateral hemisphere and the GFAP immunoreactive cells with its regular stellate morphology with nonpreferred shape distribution. Panel $\mathrm{C}$, show immunopositive cells to the cancer markers CD133, Panel D, exhibits the DAPI stained nuclei. Panel E, merge of $\mathrm{DAPI}$ and CD133 is observed in the tumor. F-H, Sox 2 tumor marked cells. F: Sox tumor marker in glioma tissue, G: nuclei DAPI marked cells (blue). $\mathrm{H}$ : merge of SOX2 and DAPI in tumor cells. Scale bars $=20 \mu \mathrm{m}$. 
Citation: Aguilar-García IG, Galván-Ramírez MD, Dueñas-Jiménez SH, Castañeda-Arellano R, Rivas-Carrillo JD, et al. (2017) Anastrozole Reduce Cell Proliferation and Induce Apoptosis in Glioblastoma Multiforme Xenograft Mouse Model. J Cancer Sci Ther 9: 655-660. doi:10.4172/19485956.1000488

The proliferation of the GBM cells in brain tissue was performed using antibody anti- Ki67. The animals treated with anastrozole at $0.1 \mathrm{mg} / \mathrm{kg}$ exhibited a considerable reduction of the number of Ki67 immunofluorescent cells, $28 \pm 2.2$, in tumor specimens, whereas, it was $61 \pm 3.7$ in the control group, with a significant difference of $\mathrm{p}<0.001$, (Figures 5A-5C).

Cell immunoreactivity to anti-aromatase in the tumor tissue was reduced in the animals treated with anastrozole, compared to the untreated group (Figures 6A-6F). In animals treated with anastrozole, aromatase protein expression was reduced $95 \%$, compared to untreated animals, with a significant difference of $\mathrm{p}<0.05$. (Figures $6 \mathrm{G}$ and $6 \mathrm{H}$ ).

The expression of estrogen receptor alpha (ERa), in GBM tumor tissue was increased, compared to control, as shown qualitatively by immunofluorescence in Figures 7A-7H. Quantitatively (Western blot), it increased $20 \%$ approximately with a significant difference $(\mathrm{p}<0.05)$ (Figures 7I and 7J).

GPR30 immunoflourecent cells decreased due to the effect of anastrozole in tumor tissue (Figures 8A-8F). Cells immunofluorescent to anti-caspase 8 were all but almost absent in untreated animals
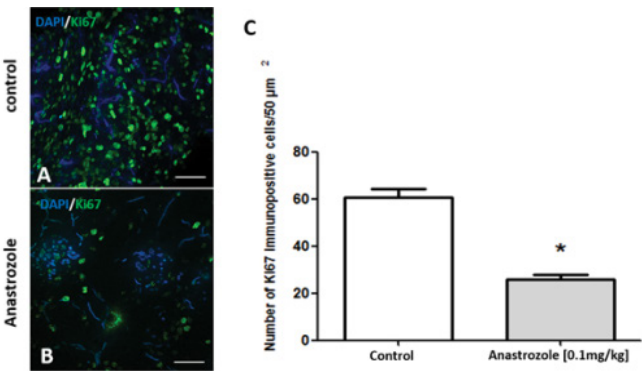

Figure 5: Effect of anastrozole on cellular proliferation in tumor tissue. The figure show sections tumor tissues immunopositive to Ki67. Figure A, exhibit microphotographs obtained from a tumor sample from untreated animals. Notice a large number of Ki67 immunofluorescent cells. In B, the group of animals treated with anastrozole show a significant decrease in the number of cells proliferating C: The graph shows the groups, control and treated with anastrozole (gray and white bar, respectively). The number of Ki67 cells significantly decreases in the treated tumor tissue, with a statistical significant difference; $p(<0.05)$. Each column represents the mean $\pm S D$, data were analyzed using t test and by Mann Whitney $U$ test.
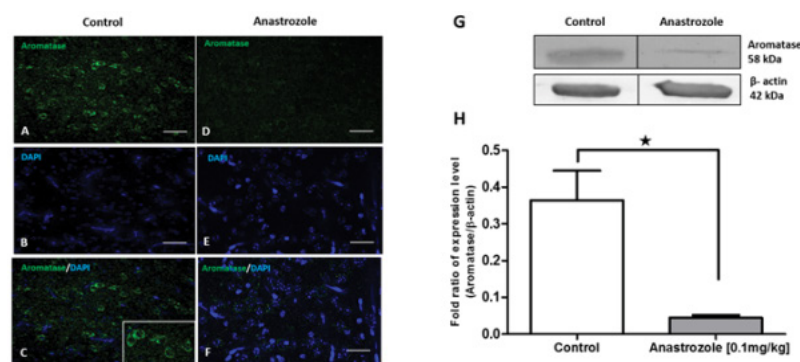

Figure 6: Expression of aromatase in tumor tissue by effect of anastrozole. In A, D show the aromatase expression (green colored) in control and anastrozole groups respectively. In $\mathrm{B}, \mathrm{E}$ the tumor cell nuclei are stained with DAPI and is shown in blue color. In $\mathrm{C}$ and $\mathrm{F}$ the merge between aromatasa and DAPI is shown. Observe that in $F$ there is an important decrease in the aromatase immunopositive cells. G) Western blotting analysis of Aromatase and $\beta$-actin. $\mathrm{H}) \mathrm{Graph}$ of the index between aromatase expression vs $\beta$-actin expression. The aromatase index expression of control group is exhibited in white bar; anastrozole tumor tissue is shown by gray bar. Note a decrease in aromatase expression index in treated tumor tissue. It had a statistical significant difference of $p<0.05$. Each bar represents the mean $\pm S D$, data were analyzed using $t$ test followed by Mann-Whitney U.
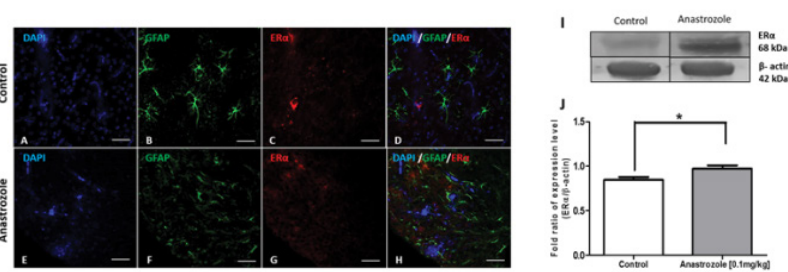

Figure 7: Effect of anastrozole on ERa expression in tumor tissues. A-D no treated tumor tissue. A show GFAP immunopositive cells, B, immunopositive ERa cells in red. C, cell nuclei stained with DAPI, D, Merge of GFAP, ERa and DAPI. E-H anastrozole tumor tissue. E: GFAP positive cells, F: immunopositive ERa cells in red, G, DAPI positive cells, $H$ merge of GFAP, ERa and DAPI. I: Western blot for ERa. J, Graph Index between ERa expression and $\beta$-actin, in tumor tissue of untreated (white bar) and treated (gray bar) mice. Notice a statistical significant increase in the $E R \alpha,(p<0.05)$. Each bar represents the mean $\pm S D$, data were analyzed using $t$ test followed by Mann-Whitney $U$.

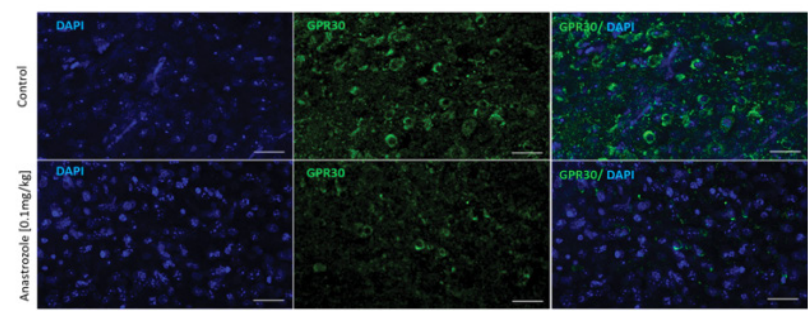

Figure 8: Effect of anastrozole on GPR30 expression in tumor tissues. In control tumor tissue $(A-C)$ and anastrozole treated group $(D-F)$. Figures $A$ and $D$ illustrate DAPI stained nuclei. Figures $B$ and $E$, GPR30 expression and $C$ and $F$ merge between GPR30 and DAPI. Note that there is an important decrease in GPR30 in the group treated with anastrozol in relation to the group not treated.
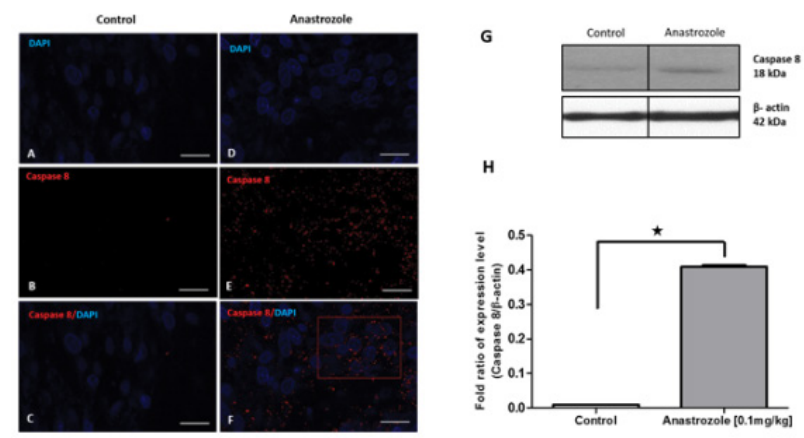

Figure 9: Expression of caspase 8 in tumor tissues treated with anastrozole. The figure show tumor sections stained with anti- caspase 8, DAPI as well as their merge. In A and D, the nucleus were stained with DAPI, in control and in anastrozole treated tumor tissue, respectively. $B$ and $E$ show immunoreactivity to caspase 8 . In figure $C$ and $F$ merge of caspase 8 and DAPI. G) Western blotting analysis of caspase 8 and $\beta$-actin. $\mathrm{H}$ : Index of caspase 8 expression vs $\beta$-actin. White bar caspase 8 expression in untreated tumor tissue and gray bar in treated tumor tissue. Note an index increase in anastrozole tumor tissue with a statistical significant difference $(p<0.05)$. Each bar represents the mean $\pm S D$, data were analyzed using $t$ test followed by Mann-Whiney $U$.

(Figures 9A-9F), whereas a great number of immunopositive cells were present in the anastrozole treated group, (Figures 9G and 9H). The caspase 8 protein expression increased in the tumor tissue treated with anastrozole $(0.01 \mathrm{mg} / \mathrm{kg})$ during 7 days after Xenograft, compared to control (Figure 8). Notice the huge increase with a statistically significant difference $(\mathrm{p}<0.05)$.

Cells immunofluorescent to anti caspase 9 were all but almost absent in untreated animals (Figures 10A-10C), whereas in anastrozole treated group, a great number of cells immunopositive to caspase 


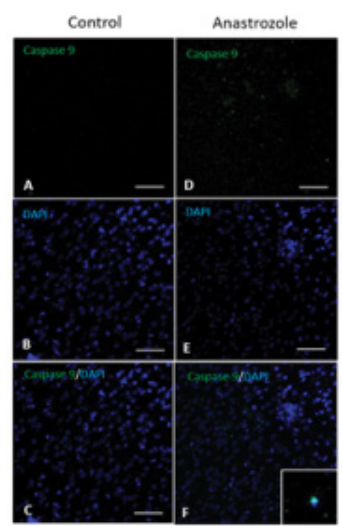

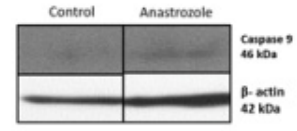

H

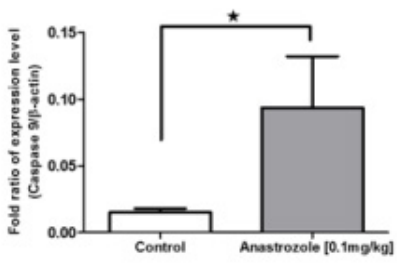

Figure 10: Expression of caspase 9 in tumor tissues by effect of anastrozole. The figure show tumor sections stained anti- caspase and DAPI in treated and untreated tumor tissue. In $A$ and $D$ cell immunoreactivity to caspase 9 is illustrated. $B, E$ the cell nuclei were stained with DAPI. $C$ and $F$ show the merge between caspase 9 and DAPI. G) Western blot of caspase 9 and $\beta$-actin proteins. $\mathrm{H}$ : Index of caspase 9 expression vs $\beta$-actin. White bar exhibits the untreated tumor tissue, gray bar represent anastrozole treated tumor tissue. Note a caspase 9 index increase in anastrozole treated tumor. This increase have a statistical significant difference of $p<0.05$. Each bar represents the mean $\pm \mathrm{SD}$, data were analyzed using $t$ test, followed by Mann-Whitney $U$.

9 were observed (Figures 10D-10F). The pro-caspase 9 protein expression augmented significantly $(\mathrm{p}<0.05)$ in the treated anastrozole group, compared to control group (Figures $10 \mathrm{G}$ and $10 \mathrm{H}$ ). Anastrozole induced the activation of caspase 8 and pro-caspase 9 in tumor tissue of experimental groups.

\section{Discussion}

GBM cells have a large heterogeneity in their gene expression changing the normal expression in estrogen receptors ERa and ERß $[6,7,12,13]$. Abnormal expression of these receptors, contribute to GBM aggressiveness and malignancy with poor response to conventional treatments. It has been described that estrogens play an important role in in vitro and in vivo models of cancer proliferation. Indeed, several types of tumors synthesize estrogens and express estrogen receptors having a fundamental role in the growth of breast, endometrium, lung and prostate cancer $[5,14,15]$. Therefore, medication inhibiting estrogen synthesis or regulating estrogen receptor expression is an alternative for cancer therapy.

Third-generation aromatase inhibitors, such as anastrozole, have demonstrated a high effectiveness in reducing estrogen levels over $96 \%$ and this change is associated with a decrease in cell viability and growth in breast cancer [16]. Anastrozole is more effective than tamoxifen and Megestrol acetate in breast cancer treatment [3]. Anastrozole reduces tumor volume when administered at a $1 \mathrm{mg}$ daily dose in postmenopausal women suffering advanced breast cancer [17].

In this study, the effect of anastrozole was evaluated for the first time in models of glioblastoma multiforme in vitro and in vivo. In vitro, the percentage of viable C6 cells decreased 95\% under anastrozole treatment. These results are similar to those described in non-small cell lung cancer where anastrozole significantly reduced cell viability. Interestingly, an aromatase enzyme activity decrease occurred [5].

It has also been observed that due to the anastrozole effect, there is a decrease in the Ki67 index in breast cancer patients [18]. It is very important to mention that our results show a significant decrease in the number of Ki67 immunofluorescent cells in anastrozole treated groups; these results could indicate a mechanism for controlling tumor growth by reducing cell proliferation. It suggests that the proliferation of malignant C6 cells in mice with Xenograft may be controlled by reducing estrogen levels and deserves to be studied in further experiments. In patients with GBM localized in frontal lobule, there is also an increase in the Ki67 proliferation marker index. However, the anastrozole effect was not evaluated as we made in these experiments [19]. In human breast cancer, patients treated with anastrozole showed a reduction in $\mathrm{Ki} 67$ index, two months after the treatment onset [20]. In mouse lung cancer induced by tobacco carcinogen NNK, anastrozole also produce a decrease in the Ki67 cell proliferation index demonstrating the effectiveness of this medication in several cancer types [21]. Thus, our results encourage us to test this medication for GBM treatment in the human being.

ERa expression has been associated to tumorigenesis. A decrease in ERa expression occurred in high grade astrocytomas biopsies $[6,22]$. In this work, we observe an ERa increase after anastrozole treatment. The mechanism should be studied to get a final conclusion. Anastrozole did not directly interact with ERa. Perhaps the expression of this receptor could be modulated by other molecules, such as insulin like growth factor (IGF-1) and fibroblast growth factor (FGF) [23], In breast cancer, the ERa did not change by anastrozole [24]. Thus, this is the first study showing an increase in ERa expression in a GBM model. This increase and its function in GBM should be determined. GPR30 is a membrane receptor promoting non-genomic intracellular pathways; this receptor is expressed in breast, lung and endometrial cancer. In this work, we observe the GPR30 expression in GBM specimens. Immunofluorescence detecting this receptor was reduced by anastrozole. It is necessary use a quantitative method for evaluating GPR30 expression. However, is interesting that for first time the presence of this receptor and their qualitative reduction in GBM cells is reported.

The use of AI for treating gliomas has been not fully explored. However, Dave et al. described that letrozole an AI significantly reduced tumor volume (75\%) in a GBM rat model, eight days after the treatment onset. These authors report a marked reduction in aromatase expression [25]. In this work, we also observe a significant reduction in aromatase expression in tumor tissue treated with anastrozole.

This reduction could contribute to decreasing tumor growth. However, subsequent studies are necessary for corroborating this hypothesis. In this work, we evaluated the expression of caspases 8 and 9 under treatment with anastrozole. Interestingly, we observed that the expression of caspase 8 activated increased in the groups treated with anastrozole. It indicates a probable participation of anastrozole in apoptosis, through the extrinsic apoptosis pathway.

It has been shown that in glioblastoma patients, the caspase 8 gene promoter has a methylation status and has been observed in melanomas [26], medulloblastomas [27], gastric carcinoma [28] and glioblastoma [29]. It could contribute to the heterogeneity of these tumors participating in pharmacological resistance [30]. The low or non-expression of caspase 8 in GBM patients has a negative prognostic for patient survival [31]. Therefore, anatrazole could be a new therapeutic strategy.

Caspase 9 is a mitochondrial pathway apoptosis initiator. Thiantanawhat described that Caspase 9 is activated by Letrozole $(1000 \mathrm{nM})$ plus androstenedione $(25 \mathrm{nM})$, as well as anastrozole $(1000$ $\mathrm{nM})$ combined with androstenedione $(25 \mathrm{nM})$ promoting apoptosis in MCF7 breast cancer cells. However the cells were transfected to 
Citation: Aguilar-García IG, Galván-Ramírez MD, Dueñas-Jiménez SH, Castañeda-Arellano R, Rivas-Carrillo JD, et al. (2017) Anastrozole Reduce Cell Proliferation and Induce Apoptosis in Glioblastoma Multiforme Xenograft Mouse Model. J Cancer Sci Ther 9: 655-660. doi:10.4172/19485956.1000488

produce aromatase. Furthermore, Letrozole induced the activity of the executioner caspases 6 and 7 and promoted regression of MCF-7a tumors. In this study, we evaluated pro-caspase 9 expression by western blotting analysis and was increased by anastrozole, with a significant difference in regard to the untreated group. This result suggests that anastrozole could induce apoptosis in GBM tumors [32].

\section{Conclusion}

Anastrozole reduces the cell proliferation and induces apoptosis in GBM cells. Aromatase was reduced by the effect of anastrozole. Therefore, it could be used as a medication for GBM treatment.

\section{References}

1. Parsons DW, Jones S, Zhang X, Lin JC, Leary RJ, et al. (2008) An integrated genomic analysis of human glioblastoma multiforme. Science 321: 1807-1812.

2. Dunn GP, Rinne ML, Wykosky J, Genovese G, Quayle SN, et al. (2012) Emerging insights into the molecular and cellular basis of glioblastoma. Genes Dev 26: 756-784.

3. Xanthopoulos JM, Romano AE, Majumdar SK (2005) Response of mouse breast cancer cells to anastrozole, tamoxifen, and the combination. J Biomed Biotechnol 1: 10-19.

4. Body JJ, Bergmann P, Boonen S, Boutsen Y, Devogelaer JP, et al. (2007) Management of cancer treatment-induced bone loss in early breast and prostate cancer a consensus paper of the belgian bone club. Osteoporos Int 18: $1439-1450$

5. Weinberg OK, Marquez-Garban DC, Fishbein MC, Goodglick L, Garban HJ, et al. (2005) Aromatase inhibitors in human lung cancer therapy. Cancer Res 65: 11287-11291.

6. Duenas Jimenez JM, Candanedo Arellano A, Santerre A, Orozco Suarez S, Sandoval Sanchez H, et al. (2014) Aromatase and estrogen receptor alpha mRNA expression as prognostic biomarkers in patients with astrocytomas. J Neurooncol 119: 275-284.

7. Yague JG, Lavaque E, Carretero J, Azcoitia I, Garcia-Segura LM (2004) Aromatase, the enzyme responsible for estrogen biosynthesis, is expressed by human and rat glioblastomas. Neurosci Lett 368: 279-284.

8. Toderow V, Rahmeh M, Hofmann S, Kirn V, Mahner S, et al. (2017) Promoto analysis of ESR1 in endometrial cancer cell lines, endometrial and endometriotic tissue. Arch Gynecol Obstet 296: 269-276.

9. Venkatakrishna RJ, Brandie NR, Bodduluri H, Carolyn MK (2012) Enhanced expression of G-protein coupledestrogen receptor (GPER/GPR30) in lung cancer. BMC Cancer 12: 624

10. He YY, Cai B, Yang YX, Liu XL, Wan XP (2009) Estrogenic G protein-coupled receptor 30 signaling is involved in regulation of endometrial carcinoma by promoting proliferation, invasion potential, and interleukin-6 secretion via the MEK/ERK mitogen-activated protein kinase pathway. Cancer Sci 100: 10511061.

11. Vergote I, Bonneterre J, Thürlimann B, Robertson J, Krzakowski M, et al. (2000) Randomised study of anastrozole versus tamoxifen as first-line therapy for advanced breast cancer in postmenopausal women. Eur J Can 36: 84-85.

12. Verhaak RG, Hoadley KA, Purdom E, Wang V, Qi Y, et al. (2010) Integrated genomic analysis identifies clinically relevant subtypes of glioblastoma characterized by abnormalities in PDGFRA, IDH1, EGFR, and NF1. Cancer Cell 17: 98-110.

13. Parker NR, Khong P, Parkinson JF, Howell VM, Wheeler HR (2015) Molecular heterogeneity in glioblastoma: Potential clinical implications. Front Oncol 5: 55.

14. Brueggemeier RW, Richards JA, Joomprabutra S, Bhat AS, Whetstone JL (2001) Molecular pharmacology of aromatase and its regulation by endogenous and exogenous agents. J Stero Biochem Mol Biol 79: 75-84.
15. Lau KM, To KF (2016) Importance of estrogenic signaling and its mediated receptors in prostate cancer. Int J Mol Sci 17: 1434-1482.

16. Ingle JN, Buzdar AU, Schaid DJ, Goetz MP, Batzler A, et al. (2010) Variation in anastrozole metabolism and pharmacodynamics in women with early breast cancer. Cancer Res 70: 3278-3286.

17. Lerebours F, Rivera S, Mouret-Reynier MA, Alran S, Venat-Bouvet L, et al (2016) Randomized phase 2 neoadjuvant trial evaluating anastrozole and fulvestrant efficacy for postmenopausal, estrogen receptor-positive, human epidermal growth factor receptor 2-negative breast cancer patients: Results of the UNICANCER CARMINA 02 French trial (UCBG 0609). Cancer 122: 30323040 .

18. Dowsett M, Smith IE, Ebbs SR, Dixon JM, Skene A, et al. (2006) Proliferation and apoptosis as markers of benefit in neoadjuvant endocrine therapy of breast cancer. Clin Cancer Res 12: 1024-1030.

19. Paldor I, Pearce FC, Drummond KJ, Kaye AH (2016) Frontal glioblastoma multiforme may be biologically distinct from non-frontal and multilobar tumors. J Clin Neurosci 34: 128-132.

20. Madeira M, Mattar A, Logullo AF, Soares FA, Gebrim LH (2013) Estrogen receptor alpha/beta ratio and estrogen receptor beta as predictors of endocrine therapy responsiveness-a randomized neoadjuvant trial comparison between anastrozole and tamoxifen for the treatment of postmenopausal breast cancer. BMC Cancer 13: 425.

21. Stabile LP, Rothstein ME, Cunningham DE, Land SR, Dacic S, et al. (2012) Prevention of tobacco carcinogen-induced lung cancer in female mice using antiestrogens. Carcinogenesis 33: 2181-2189.

22. Liu MH, Cheung E (2014) Estrogen receptor-mediated long-range chromatin interactions and transcription in breast cancer. Mol Cell Endocrinol 382: 624632.

23. Siegfried JM, Farooqui M, Rothenberger NJ, Dacic S, Stabile LP (2017) Interaction between the estrogen receptor and fibroblas growth factor receptor pathways in non-small cell lung cancer. Oncotarget 8: 24063-24076.

24. Rechoum Y, Rovito D, lacopetta D, Barone I, Ando S, et al. (2014) AR collaborates with ERalpha in aromatase inhibitor-resistant breast cancer Breast Cancer Res Treat 2014; 147: 473-485.

25. Dave N, Chow LM, Gudelsky GA, LaSance K, Qi X, et al. (2015) Preclinical pharmacological evaluation of letrozole as a novel treatment for gliomas. Mo Cancer Ther 14: 857-864.

26. Bae SI, Cheriyath V, Jacobs BS, Reu FJ, Borden EC (2008) Reversal of methylation silencing of Apo2L/TRAIL receptor 1 (DR4) expression overcomes resistance of SK-MEL-3 and SK-MEL-28 melanoma cells to interferons (IFNs) or Apo2L/TRAIL. Oncogene 27: 490-498.

27. Aguilera DG, Das CM, Sinnappah-Kang ND, Joyce C, Taylor PH, et al. (2009) Reactivation of death receptor 4 (DR4) expression sensitizes medulloblastoma cell lines to TRAIL. J Neurooncol 93: 303-318.

28. Lee KH, Lim SW, Kim HG, Kim DY, Ryu SY, et al. (2009) Lack of death receptor 4 (DR4) expression through gene promoter methylation in gastric carcinoma. Langenbecks Arch Surg 394: 661-670.

29. Martinez R, Setien F, Voelter C, Casado S, Quesada MP, et al. (2007) CpG island promoter hypermethylation of the pro-apoptotic gene caspase- 8 is a common hallmark of relapsed glioblastoma multiforme. Carcinogenesis 28 : 1264-1268.

30. Fulda S, Debatin KM (2007) HIF-1-regulated glucose metabolism: a key to apoptosis resistance? Cell Cycle 6: 790-792.

31. Skiriute D, Vaitkiene P, Saferis V, Asmoniene V, Skauminas K, et al. (2012) MGMT, GATA6, CD81, DR4, and CASP8 gene promoter methylation in glioblastoma. BMC Cancer 12: 218

32. Thiantanawat A, Brian JL, Brodie MA (2003) Signaling pathways of apoptosis activated by aromatase inhibitors and antiestrogens. Cancer Research 63 . 8037-8050. 